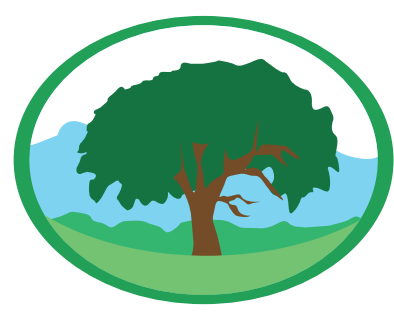

\title{
A multidimensionalidade da sustentabilidade: Percepções em um agroecossistema de base familiar característico de assentamentos de reforma agrária
}

ANDERSSON, NORBERTO L.M.'; NORONHA, ANA P. '; ÁVILA, DANTE T. DE'; COSTA, JAKES H. DE Q.';

CASALINHO, HÉLVIO D. ${ }^{3}$

'Doutor no Programa de Pós Graduação em Sistemas de Produção Agrícola Familiar. Universidade Federal de Pelotas - UFPEL

${ }^{2}$ Mestre no Programa de Pós Graduação em Sistemas de Produção Agrícola Familiar. Universidade Federal de Pelotas - UFPEL

${ }^{3}$ Professor Doutor no Programa de Pós Graduação em Sistemas de Produção Agrícola Familiar. Universidade Federal de Pelotas - UFPEL

Palavras-chaves: agroecologia, agricultura familiar, assentamento rural

\section{Resumo}

Este trabalho faz-se relevante por desenvolver a temática da multidimensionalidade da sustentabilidade em agroecologia, onde este diferencial manifesta uma alternativa de produção livre de agrotóxico, melhorando a qualidade de vida do produtor, da sua família que se abastece de sua produção, bem como de seus consumidores. Ações estas que se alinham com a proposta de desenvolvimento rural sustentável, baseada na sustentabilidade do agroecossistema. 0 objetivo foi apreciar, na forma exploratória, a muldimensionalidade da sustentabilidade em uma propriedade agrícola familiar do sul do Rio Grande do Sul, a partir de uma visita realizada em um lote de produção de base agroecológica, no Assentamento Conquista da Liberdade, no município de Piratini - RS. Trata-se, portanto, de pesquisa exploratória. No desenvolvimento das atividades foram utilizadas ferramentas/instrumentos denominadas de metodologias participativas envolvendo uma observação participante, como uma ferramenta de diagnóstico rural participativo, denominada de caminhada, auxiliada por técnica de reunião problematizadora, complementada por entrevista semiestruturada. Ações estas viabilizadas no decorrer do mês de fevereiro de 2013. Como conclusão, tem-se que os agricultores familiares na propriedade estudada indicam e caracterizam - sistema de produção como de base ecológica apresentando os seguintes atributos: adaptabilidade, estabilidade, produtividade, resiliência, complexidade, equidade e autogestão. Observa-se uma preocupação na continuidade da busca da sustentabilidade deste agroecossistema, denotando-se uma referência com o social, com o ambiental, com o econômico, com o cultural, com o político e com o ético.

\section{The multidimensionality of sustainability: Insights into a family-based agro-ecosystem} characteristic of agrarian reform

Keywords: agroecology, family farm, rural settlement

\section{Abstract}

This work is relevant for developing the theme of sustainability in agroecology, where this differential manifests an alternative pesticide-free production, improving the quality of life of the producer, their families which obtain supplies of their production, as well as their consumers. These actions are in line with the proposal of sustainable rural development, based on the sustainability of agroecosystems. The aim was to assess, in an exploratory way, sustainability on a family farm in southern Rio Grande do Sul, from a visit made in a production batch 
of agroecological base, in the Conquista da Liberdade Settlement, in Piratini - RS. It is therefore an exploratory research. Tools/instruments denominated participatory methodologies were used in the development of activities involving participant observation as a tool of participatory rural appraisal, called walking, aided by problematizing technical meeting, complemented by semistructured interview. In conclusion, family farmers on the property studied indicate and characterize the system of production as ecology-based presenting the following attributes: adaptability, stability, productivity, resilience, complexity, equity, and self-management. There has been a concern in the continuity of the pursuit of sustainability of this agroecosystem, denoting a reference to the social, the environmental, the economic, the cultural, the political, and the ethical.

\section{INTRODUÇÃO}

A agricultura é multidimensional e traz consigo valores culturais reproduzidos pelas sociedades ao longo de seu processo de coevolução com a natureza. Essa relação não se dá apenas pelo desenvolvimento de tecnologias para cultivar a terra, mas também pela produção de padróes culturais humanos, tais como: consumo e produção de alimentos (PLOEG, 2008; SCHNEIDER, 2006).

Dentro desta perspectiva agrícola, destaca-se a agricultura familiar como uma categoria social que associa três elementos fundamentais: famíliaprodução-trabalho, os quais permitem a agricultura familiar apresentar diferentes estilos de produção e reproduçâo social, por meio de diversas estratégias ambientais, econômicas, sociais e de produção em diversos agroecossistemas, ao longo da história (WANDERLEY, 1999).

No Brasil, segundo dados do censo agropecuário de 2006 (IBGE), a agricultura familiar é a categoria social detentora da maioria das unidades produtivas $(84,4 \%)$. Em contraponto, elas ocupam $24,3 \%$ das áreas utilizadas pelos estabelecimentos agropecuários do país. Esta categoria social emprega $74,4 \%$ da mão de obra no campo e é responsável pela segurança alimentar e nutricional do país, gerando parte da diversidade dos produtos que integram a cesta básica consumida pelos brasileiros.

O Rio Grande do Sul é o terceiro estado brasileiro com o maior número de estabelecimentos da agricultura familiar $(85,5 \%)$, os quais representam
80,5\% das ocupaçóes do Estado. No que tange ao emprego de máo de obra, a agricultura familiar, emprega 1.231.820 trabalhadores (IBGE, 2006). Desta maneira, esta categoria social demonstra seu importante papel no cenário agrário, agrícola, social e econômico no Rio Grande do Sul e no Brasil.

Apesar da inquestionável importância da agricultura familiar para o desenvolvimento socioeconômico, esse segmento foi fortemente marginalizado pelo processo de modernizaçáo da agricultura, conhecido como Revolução Verde (ABRAMOVAY, 2007; BALSAN, 2006; SILVA, 1982). Um dos grandes problemas enfrentados foi e ainda é a falta de adequação das tecnologias propostas, inadequadas aos sistemas de produção agrícola familiar. $\mathrm{Na}$ maioria dos casos, isso ocorre principalmente porque foram produzidas sem considerar as condiçóes socioeconômicas e agroecológicas dos agricultores, assim como a sua racionalidade particular e peculiar (CHAMBERS et al., 1989; MOTA et al., 2007; SCHMITZ et al., 2004).

Flores e Silva (1992) chamam a atenção para a artificialidade socioeconômica do modelo vigente, em que o sistema de apoio técnico, representado pelos órgãos de pesquisa e extensão rural, foi organizado conforme um modelo linear de geração e transferência de tecnologia, estruturado "por produto" (milho, arroz, leite, fumo, etc.), e sintetizado pelo trinômio crédito, pesquisa e extensão. Segundo eles, pelo modelo atual, as tecnologias produzidas pela pesquisa deveriam ser levadas pela extensão rural aos agricultores que deveriam ser convencidos da superioridade e da legitimidade das novas técnicas.

Assim, as propriedades agrícolas familiares transmitem a ideia de que deveria ser possível uma produção diversificada com relação a produtos de origem animal e vegetal, tendo em vista uma relaçáo de resgate com o campesinato, conforme Abramovay (2007). Um diferencial poderia vir a ser uma produção de produtos manejados com cuidados ecológicos, contemplando as dimensões econômicas, sociais, ambientais e culturais, não esquecendo também a dimensão política associada à ética.

A expansão e o dinamismo da agricultura familiar basearam-se na garantia do acesso à terra que em 
cada país assumiu uma forma particular, desde a abertura da fronteira oeste americana aos farmers até a reforma agrária compulsória na Coreia e em Taiwan. Em todos estes países, além de contribuir para dinamizar o crescimento econômico, a agricultura familiar desempenhou um papel estratégico que tem sido relevado em muitas análises: o de garantir uma transição socialmente equilibrada entre uma economia de base rural para uma economia urbana industrial (GUANZIROLI et al., 2001).

Neste universo da agricultura familiar estão inseridos os assentamentos rurais que, conforme Bergamasco e Norder (1996), representam uma forma de se fazer Reforma Agrária no Brasil, consoante o Plano Nacional de Reforma Agrária vigente, que têm ganhado destaque no cenário nacional no transcorrer das três últimas décadas, como uma tentativa de amenizar a violência dos conflitos sociais no campo, a partir dos anos 80.

Segundo Medeiros e Leite (2004), o termo assentamento é usado normalmente para generalizar uma série de intervenções fundiárias do poder público unificando uma grande quantidade de açóes tais como a regularização da posse da terra, a fixação de rendeiros à terra, a distribuição às famílias sem terras; a realocação de famílias, etc.

\section{REFERENCIAL TEÓRICO}

A Agroecologia é considerada um novo enfoque científico que representa um salto de qualidade na direção da agricultura com sustentabilidade em seus aspectos multidimensionais. Ademais, ela também é vista como estratégia metodológica de transformação social (SEVILHA-GUZMÁN, 2001).

Tendo o agroecossistema (produto da evolução homem/natureza) como unidade de estudo, a matriz do conhecimento agroecológico interliga dois princípios fundamentais: a preservação e ampliação da biodiversidade dos agroecossistemas (saúde ecológica), com o objetivo de atingir a autorregulaçáo e sustentabilidade biológicas nos complexos sistemas agrícolas, para que as "interaçôes ecológicas e a sinergia entre os componentes biológicos criem, eles próprios, a fertilidade do solo, a produtividade e a proteção das plantas" (ALTIERI, 1989); e a preservação da diversidade cultural das populaçóes (saúde cultural), onde se reporta à atuação sócio-cultural dos agricultores em suas respectivas localidades, que trabalham o agroecossistema de acordo com conhecimentos acumulados da interaçáo entre os elementos da natureza, os organismos vivos e suas práticas agrícolas.

Estas propriedades poderiam partir diretamente de uma produçáo ecológica, sem terem que passar por um período de transição, convencional-ecológico, ao visualizar um mercado latente, que se encarregue de absorver este produto com alto apreço pela vida. Vida saudável, agora e para a geração futura, estando relacionada à saúde do produtor e do ambiente que o cerca. Isto com certeza parte de uma mudança do modo de pensar, mudança de como eleger valores, mudança do modo de olhar o mundo, mudança do que queremos agora para nós, sem esquecermos as geraçóes futuras que virão, ao necessitarem de uma continuidade nesta forma de produzir.

Segundo a abordagem de Capra (1996), há necessidade de uma mudança profunda de percepção e de pensamento para garantir a nossa sobrevivência. Para tanto, é preciso haver uma mudança do paradigma tradicional, com visáo do universo como um sistema mecânico, para um novo paradigma com visão ecológica profunda, onde tudo está encaixado nos processos cíclicos da natureza. Assim, a percepção ecológica profunda parece fornecer a base filosófica e espiritual ideal para um estilo de vida ecológico e para o ativismo ambientalista. Com isso, a nova ciência da ecologia enriqueceu a emergente maneira sistêmica de pensar introduzindo duas novas concepçóes: comunidade e redes. Desde que os sistemas vivos, em todos os níveis, são redes, deve-se visualizar a teia da vida como sistemas vivos (redes) interagindo à maneira de rede com outros sistemas (redes), ou seja, a teia da vida consiste em redes dentro de redes.

Sobre a abordagem sistêmica, Schmitz (2005) revela que esta foi introduzida em pesquisa e extensão rural em funçáo das críticas nos impactos da Revolução Verde. Sendo que, em pesquisa e extensão, foram desenvolvidas novas abordagens para atender as necessidades dos agricultores em condiçóes menos favoráveis. Ainda, no enfoque sistêmico, a propriedade agrícola é vista como uma unidade complexa, 
administrada pela família, abrangendo tanto o sistema de produçáo como o de consumo. Assim, a inovação se torna um processo complexo, que normalmente está ligado a alteraçôes profundas dentro desses sistemas.

A agroecologia, para Guzman Casado, Gonzalez Molina e Sevilla Guzman (2000), poderia ser definida como uma abordagem teórica e metodológica que pretende estudar a atividade agrária a partir de uma visão ecológica. Sua vocação é a análise de todos os processos e interaçóes dos tipos agrários em um sentido amplo, ou seja, análise do todo e não apenas das partes. Com isso, a agroecologia pretende inserir-se em um novo paradigma em formaçáo, produto da crise entre os paradigmas tradicionais e da racionalidade científica-técnica que os ampararam.

Deste modo, o paradigma (ecológico) é evolucionista e também rompe com a tendência mecanicista analítica que mantém uma consideraçáo atômica da realidade. Ainda, conforme esses autores, o conhecimento campesino e as estruturas de ação da agroecologia, deixando explícita a contribuição, vasta e importante, desses agricultores para a agroecologia, como por exemplo, conhecimentos em relação à taxionomia da biologia local, sobre o meio ambiente, práticas agrícolas de produção e conhecimento campesino experimental. Por fim, concluem que a agroecologia, por seu enfoque holístico e sua perspectiva sistêmica, não termina na consideração agronômica dos agroecossistemas. A agroecologia reivindica o conceito de identidade para transmitir a necessidade de sua preservação como legado às geraçôes futuras (GUZMAN CASADO; GONZALEZ MOLINA; SEVILLA GUZMAN, 2000).

Embora a tendência seja de os filhos dos produtores agrícolas familiares irem procurar seus próprios caminhos, quando estiverem formados, o casal, neste caso de estudo, desempenha uma função de extrema importância, ao afirmar através de seu trabalho, uma segurança alimentar para si e para seus filhos que estão longe. Segundo Silvestro (2001), a expectativa profissional dos jovens agricultores é a de permanecer no meio rural, principalmente em áreas que eles tenham a incumbência da gestão.

Uma propriedade agrícola familiar com produção de base ecológica, que se sustenta economicamente, interage socialmente, caracteriza-se ambientalmente e produz culturalmente alimentos sadios, tornase importante como estímulo ao desenvolvimento sustentável no meio rural, ao levar em consideração as perspectivas com relação ao tempo do retorno econômico, forma de produzir, mercado e mão de obra utilizada.

A reforma agrária no Brasil é fruto de um processo histórico que tem suas raízes na própria colonização do Brasil (OLIVEIRA; STEDILE, 2005), sendo um tema bastante discutido, principalmente sobre sua viabilidade econômica e sua necessidade no processo de desenvolvimento da agricultura brasileira (GORGEN; STÉDILE, 1991; GUANZIROLI; FALCÃO, 2012), sendo indiscutível a sua necessidade social. Como bem colocam Bergamasco e Norder (1996) "as interpretaçôes sobre os assentamentos carregam concepçóes sobre reforma agrária, desenvolvimento agrícola e sobre a própria sociedade". Entretanto, a sua viabilização encerra uma série de problemas atinentes à infraestrutura social (saúde, educação, transporte, moradia) e produtiva (terras férteis, assistência técnica, eletrificação, apoio creditício e comercial), conforme alertam Bergamasco e Norder (1996), cuja primeira dificuldade refere-se à organização da produção, logo após à instalação no assentamento (SILVA, 2001).

Trata-se de um processo, segundo Cavalcante (2007), marcado por conflitos internos e externos que provocam alteraçóes nas vidas dos assentados e na região de sua implantação, que tem sido impulsionado pela pressão dos movimentos sociais sobre o governo federal (GUANZIROLI; FALCÃO, 2012).

\section{MATERIAL E MÉTODOS}

A propriedade agrícola estudada localiza-se no Assentamento Conquista da Liberdade, $2^{\circ}$ Distrito do município de Piratini - RS. Estabelecido em fevereiro de 1992, o assentamento Conquista da Liberdade, com uma área de 1.232 hectares, recebeu inicialmente 50 famílias. A área pertencia anteriormente a uma empresa do conglomerado agroindustrial denominado CICA Alimentos S/A e era destinada quase que exclusivamente à produção comercial de pêssegos.

$\mathrm{O}$ assentamento está localizado às margens da rodovia BR-293, importante via de comunicação da 
regiáo sul do estado do Rio Grande do Sul. Por estar localizada em uma regiáo de características ambientais distintas da região de origem dos agricultores assentados, oriundos do noroeste do Rio Grande do Sul, a área representou um grande desafio para o grupo. Culturalmente, essas famílias estavam envolvidas com as atividades relacionadas ao cultivo da soja, mas na área recebida as características naturais logo impuseram um primeiro grande obstáculo ao grupo, que viu sua tentativa de reproduzir as condiçóes produtivas do noroeste do Estado fracassar já na primeira safra.

\section{METODOLOGIA UTILIZADA}

Trata-se de pesquisa exploratória. No desenvolvimento das atividades foram utilizadas ferramentas/instrumentos denominadas de metodologias participativas, que valorizam os agricultores familiares, o que eles têm no local e aperfeiçoam e/ou potencializam as experiências (HABERMEIER, 1995). Dentre diversas ferramentas metodológicas o Diagnóstico Rápido Participativo (DRP) permite que os atores sociais façam o próprio diagnóstico (VERDEJO, 2006) e se consiga compreender a percepçáo da realidade da comunidade. Os instrumentos mais utilizados em um DRP são: observação participante, entrevistas semiestruturadas, mapas e maquetes, travessia, calendários, diagramas, matrizes e análise de gênero (PETERSEN; ROMANO, 1999; VERDEJO 2006).

A observação participante (VERDEJO, 2006) foi utilizada na primeira etapa da pesquisa, vez que propóe o "andar com os olhos abertos" e aproveitar as possibilidades de partilhar momentos do cotidiano com agricultores, conhecer a realidade e criar um clima de confiança.

Foi utilizada, também, a ferramenta de diagnóstico rural participativo denominada de caminhada, preconizada por Ruas et al. (2006), técnica que consiste em percorrer determinados trechos de uma propriedade, junto com participantes, para identificar e discutir diversas percepçôes das características espaciais e do agroecossistema, as formas de ocupação da terra e o modo de vida das pessoas envolvidas.

O trabalho foi auxiliado por técnica que se rotula por reunião problematizadora (RUAS et al., 2006), que permite o desenvolvimento de um processo de reflexão com base em questionamentos, confrontos e associação de ideias, sobre a realidade, a fim de se compreenderem os fenômenos objetivando a transformação. A tarefa foi complementada por entrevista semiestruturada, conforme Verdejo (2006).

\section{RESULTADOS E DISCUSSÃO}

A alegria denotada quando da entrevista, por parte do casal de proprietários, é demonstrativa de uma segurança fundamentada nos princípios do bem-estar entre ser humano e ambiente de trabalho. Trabalham naquilo que gostam de fazer sem levar em consideração apenas a parte econômica do empreendimento, mas, também os componentes sociais de relacionamento, os componentes ambientais da produçáo e os componentes culturais no resgate de saberes transmitidos pelos pais do casal, os quais também são transmitidos aos seus filhos.

Houve uma significativa afirmação em forma de confidência, por parte do casal, ao mencionar que quando uma Agricultura Familiar prioriza a monocultura como autossuficiente, esta fica a mercê de ter de comprar a maior parte do alimento que será colocado na mesa da família, no mercado, despendendo um volume considerável de dinheiro, recurso este que poderia ser direcionado à produção. Quando o preço de mercado, da produçáo desta monocultura fica em decréscimo, a situação financeira dos produtores, com relação aos alimentos consumidos diariamente pela família, tende a ficar numa situação preocupante, principalmente se a melhora no preço de venda fica cada vez mais distante.

Com relação à diversidade de produtos e produção, o sistema de produção desenvolvido pela família contempla trinta e oito espécies vegetais, destacando-se alface, tomate, uva, feijão, abóbora, pepino, cornichão, ervilhaca, rúcula, milho, beterraba, cenoura, batata inglesa, batata doce, macaxeira, cebola dentre outras, e seis espécies animais (abelha, porco, vaca, pato, peru, galinha).

Ao conversar com o casal, foi observado que, embora exista uma grande diversidade na produção da propriedade familiar, em primeiro lugar foi eleito o sustento alimentar da família, derivado desta 
diversidade produtiva, levando a uma segurança alimentar por parte de todos da família. Para terem uma estabilidade econômica, o casal optou em ter um carro chefe dentro da produção, que é o mel (desoperculado, centrifugado, filtrado e envasado), que, ao ser vendido, traz retorno financeiro ao ponto de se poder reinvestir dentro da propriedade sem necessitar pedir empréstimo ao banco.

Os resultados alcançados por experiências inovadoras em todo o mundo permitem afirmar que o enfoque agroecológico propicia o aumento da produçáo e dos rendimentos sem que seja necessário empregar insumos e equipamentos dos sistemas da Revolução Verde. Pelo contrário, são práticas que vêm se constituindo com base na valorização dos recursos locais, em particular da grande diversidade de espécies de plantas cultivadas e melhoradas pelos agricultores familiares (WEID, 2004).

Estas experiências são realizadas, no mundo em desenvolvimento, com condiçôes ambientais bem menos favoráveis do que aquelas em que cresceu o modelo da Revoluçáo Verde. A partir de pesquisas realizadas e compiladas pela Universidade de Sussex, constatou-se que o manejo agroecológico vem proporcionando aumentos médios de rendimentos da ordem de $100 \%$ e, nos casos mais avançados, quando sistemas agroecológicos mais completos e complexos foram analisados, chegaram à casa de 600\% (WEID, 2004).

O conhecimento camponês sobre os ecossistemas geralmente resulta em estratégias produtivas multidimensionais de uso da terra, que criam, dentro de certos limites ecológicos e técnicos, a autossuficiência alimentar das comunidades em determinadas regióes (TOLEDO et al., 1985). Nos agroecossistemas tradicionais, a predominância de sistemas de cultivo complexos e diversificados é de suma importância para os camponeses, na medida em que as interaçóes entre plantas cultivadas, animais e árvores resultam em sinergismos benéficos que permitem aos agroecossistemas promover sua própria fertilidade de solo, controle de pestes e produtividade (ALTIERI, 1987; RICHARDS, 1985).

Em relação à qualidade ambiental, a água como elemento imperativo da vida, é captada de uma cacimba como fonte protegida, cuja localização foi potencializada através de melhoramentos relacionados à sua higienização, para ser utilizada no consumo humano, bem como em alguns setores onde é necessária para irrigação e limpeza de instalaçôes. $\mathrm{O}$ esgoto sanitário não agride o meio ambiente onde é despejado, visto que utiliza técnicas preconizadas pela EMBRAPA (Empresa Brasileira de Pesquisa Agropecuária), como a fossa séptica biodigestora, técnica esta condizente com os princípios da saúde no meio rural, preconizadas pelos órgãos competentes como, FEPAM (Fundação Estadual de Proteção Ambiental Henrique Luiz Roessler) e SQA (Secretaria de Qualidade Ambiental) do município de PelotasRS.

Os cuidados ambientais com relação à área trabalhada são visualizados através do respeito ao ambiente, no uso de insumos, os quais são produzidos dentro da propriedade, e utilizados na pluralidade de cultivos existentes na propriedade familiar de base ecológica.

Com relação à contribuição social, na propriedade estudada, o casal que nela trabalha, produz alimentos para seu sustento, sendo uma pequena parte comercializada em feiras locais por eles ou por algum vizinho, observando-se assim, a sua participação num dos tipos de redes da sociedade moderna, as mercantis, cujos vínculos se firmam por obrigação contratual bem como em redes sociais, cujos vínculos exigem uma dimensão coletiva mais ampla conforme Caillé (1998), o ato de manter relaçóes de amizade ou camaradagem, permite conservar e esperar confiança e fidelidade. No envolvimento de vizinhos assentados encontra-se a reciprocidade positiva ou da dádiva preconizada por Sabourin (2003), associada ao dar, receber e retribuir. Constata-se, também tal prática no compartilhamento do volume maior do excedente de produção com membros da família que residem em outras localidades e municípios do Estado.

A família tem uma busca contínua de melhores níveis de qualidade de vida mediante a produção e o consumo de alimentos com qualidade nutricional, o que comporta, por exemplo, a eliminação do uso de insumos tóxicos no processo produtivo agrícola com uso de novas combinaçóes tecnológicas, ou ainda 
através de opçóes sociais de natureza ética ou moral, constatados pela percepção de riscos e/ou efeitos maléficos que o sistema de produção "convencional" acarreta para a sua reprodução social, tais como câncer, contaminação do solo e de lençóis freáticos.

Com relação à visão econômica, as atividades desenvolvidas na unidade de produção são registradas em fichas, tabelas, cadernos e documentos, guardados em pastas, em local específico. Tais registros são, indubitavelmente, de utilidade nas tomadas de decisão e contribuem, particularmente, no processo de gestáo financeira da unidade familiar.

Outro ponto diz respeito às práticas de experimentação agropecuária objeto de exercício na propriedade. $\mathrm{O}$ uso de materiais construídos ou adaptados pelos agricultores à realidade da unidade produtiva é uma constante, procurando maior rendimento, com menor custo e menor esforço físico e uso de energia (economia ecológica). Uma vez por semana o casal utiliza um quadro negro, onde lista as prioridades desta produção ecológica, descrevendo como deverá ser realizado este trabalho e qual o impacto esperado quando finalizado.

Com relação ao enfoque cultural, a família entrevistada é oriunda da região do Alto Uruguai, do município de Seberi, no Rio Grande do Sul. Assentados em Piratini, desde 1992, vêm desenvolvendo o sistema Agroecológico em seu lote atual desde 2007, com um intuito específico de trabalhar o lote orgânico, seguindo os ensinamentos dos pais, que já trabalhavam com preservaçáo de mata nativa, sementes crioulas, utilização de insumos alternativos, etc. Primeiramente, a produção é para o consumo, com utilização de adubos produzidos na propriedade. $O$ leque de produção gira em torno de 38 culturas, que integram o sistema de produçáo que envolve espécies arbóreas, forrageiras, hortícolas, medicinais, condimentares, aromáticas e melíferas, além da bovinocultura de leite, suinocultura, avicultura e apicultura, sem utilização de insumos externos e não necessitando de recursos de capital derivados de financiamentos.

A produção é diversificada, para consumo familiar utilizando-se racionalmente a área agricultável. Observa-se a diversificação na agricultura, tratada por Radomsky (2006). Parte da produção é para o consumo do casal e parte distribuída com os filhos; o que indica ser a prática da dádiva e reciprocidade uma constante no cotidiano dos agricultores (MAUSS, 1974; CAILLÉ, 1998; BOURDIEU, 1996; SABOURIN, 2003; POLANYI, 2000).

$\mathrm{O}$ pequeno excedente, normalmente de produtos processados (doce em compotas, geleia, queijo, conservas), é levado por um deles ou encaminhado por vizinhos para a feira municipal. O mel é levado por um dos filhos para a região metropolitana de Porto Alegre e as sementes são comercializadas diretamente com a Bionatur Sementes Agroecológicas. Não comercializam a produçáo na propriedade, vez que ela é vista exclusivamente como espaço de produção, não de negócio. Consideram que o dinheiro não é tudo. A unidade é espaço de produção, de visita, de acolhida de pessoas, de experimentação, de trocas de experiências, de vivência. Percebe-se o cultivo de uma racionalidade que difere da adotada pela maioria dos agricultores familiares da regiáo.

Sem dúvida, eles são protagonistas de processos sociais, sem perder sua centralidade mesmo no processo de mercantilização, resguardando tradição, cultura e história local. Do exposto se percebe a existência, conforme Wanderley (1999), de "estratégias de reprodução dos agricultores, no ambiente atual, se baseiam na valorização dos recursos disponíveis no estabelecimento familiar e se destinam a assegurar a sobrevivência da família, no presente e futuro". Ao deitar os olhos sobre o espaço de estudo constata-se, também, uma aproximação ao que escrevem Sacco dos Anjos e Caldas (2009) sobre a realidade rural quando afirmam que "os novos tempos trouxeram consigo uma série de melhorias para muitos, fruto das inovaçóes tecnológicas, mas, transforma o modo de vida que passa a ser governado pela busca por rentabilizar o uso da terra e da força de trabalho familiar".

Com relação à dimensão política, o papel do Estado é de fundamental importância desde que ele assuma como mediador da agricultura ecológica, abrindo mercados, valorizando o ser humano, estimulando o retorno dos jovens na continuidade do trabalho agrícola familiar, incentivando o envolvimento do agricultor, do consumidor e do técnico como gestores coletivos desta forma de produzir. 
Os agricultores (casal da análise) desempenham um papel político mediante participação em grupos de agricultores, associação do assentamento - instrumento de ligação com o mercado e em instituições públicas do Estado, cooperativas de apicultores - comercialização da produção, organizaçóes governamentais e náogovernamentais (socioeconômica, política e cultural), que dizem respeito ao modo de vida da família e sua inserção na sociedade.

Com relação à dimensão ética, a gestão da propriedade é objeto de decisão familiar, atualmente do casal. Os filhos são independentes e não mais residem no lote (dois são agricultores e um é técnico agrícola). O processo de tomada de decisão é dos proprietários, que planejam, executam e avaliam os processos desenvolvidos na propriedade, considerando a experiência de vida, os conhecimentos adquiridos, as informaçóes disponíveis no mercado, a troca de experiências com outros agricultores e, para algumas culturas, a orientação de técnicos vinculados à organização (Cooptec, Bionatur e Emater) para quem fornecem alguns produtos agrícolas ou recebem orientaçôes técnicas. Constata-se o envolvimento do casal em redes de relaçôes sociais fortes (filhos e parentes) e fracas (associação, cooperativa, vizinhos, técnicos, visitantes etc.) (CAILLÉ, 1998); LOWE et al., 1995); GRANOVETTER, 1973).

A mão de obra é tipicamente familiar (ele e a esposa, que residem no lote e não na Agrovila), cabendo frisar que nos últimos anos sequer fazem uso sazonalmente de mão de obra externa à família. Tudo é pensado e direcionado em função da capacidade de trabalho deles dois; a mão de obra é utilizada de acordo com uma lógica que culmine com a geração do menor esforço possível para cada realidade de trabalho, para cada um deles. Inclusive a disposiçáo espacial das exploraçóes agropecuárias é baseada para ser desenvolvida com o menor custo, menor utilização de energia e maior reutilização, na própria unidade, dos resíduos gerados na propriedade. As atividades agrícolas estão em sintonia com as de pecuária, se complementam; da unidade produtiva se extrai a maioria dos insumos de produçáo. Da unidade produtiva eles retiram praticamente os principais alimentos da dieta familiar, buscando em estabelecimentos comerciais apenas alguns poucos itens de consumo (café, açúcar entre outros).

\section{ELEMENTOS PARA UMA REFLEXÃO}

A análise da dinâmica da propriedade, feita a partir do Diagnóstico Rápido Participativo, possibilitou perceber a visão da família sobre agroecossistema, considerando-ocomoum todoorganizado, permitindo, também, o saber como é feita a gestão da propriedade agrícola familiar de base ecológica. Com a avaliação semanal o casal utiliza um quadro negro, onde lista as prioridades desta produção ecológica, descrevendo como deverá ser realizado este trabalho e qual o impacto esperado quando finalizado. Tudo é realizado de forma interligada, interdependente, traduzindo numa continuidade segura da ambientalidade do agroecossistema.

Em poucas palavras, a propriedade, foco desse diagnóstico, adota uma síntese das práticas agrícolas tradicionais, com ideias inovadoras. Os proprietários, unindo o conhecimento tradicional, passado de geração em geração, às descobertas de algumas técnicas desenvolvidas pela ciência atual, proporcionam o desenvolvimento integrado da propriedade rural. A dinâmica da propriedade envolve o planejamento, a implantação e a manutenção de técnicas, através de interferências conscientes em seu agroecossistema produtivo que tenham a diversidade, a estabilidade e a resiliência mais próxima possível dos ecossistemas naturais. Neste caso, estas intervençóes resultam na integração harmoniosa entre as pessoas e a paisagem, provendo alimentação, energia e habitação, entre outras necessidades materiais e não-materiais, caminhando em direção a formas mais sustentáveis de se relacionar com a natureza. Ou seja, compreendem perfeitamente a agricultura como uma intervenção do homem na natureza (ecossistema natural).

O casal de agricultores tem consciência da importância da biodiversidade na manutenção de agroecossistemas saudáveis no longo prazo. Sabem que todos os organismos desempenham um papel na natureza e que cada espécie tem uma função a desempenhar. Com esse entendimento, cultivam diversas espécies vegetais, seja para o consumo direto (como hortícolas e frutas), para a produção de mel 
(espécies melíferas de algumas espécies arbóreas nativas), produção de forragem para biomassa e alimentação do gado (leite), plantas medicinais, condimentares e aromáticas. Isso sem falar no belíssimo jardim repleto de cores e cheiros que, além de contribuir na qualidade de vida ofertando um aroma agradável (beleza cênica) associado a sua beleza, também atraem polinizadores que acabam por visitar suas hortas e pomares garantindo com isso uma ótima produtividade de seus cultivos. A diversidade e a estabilidade permanecem em alta, garantindo, assim, a sobrevivência da unidade produtiva no longo prazo.

A diversidade náo deve ser relacionada somente com o número de espécies ou elementos de um sistema, mas também com o número de conexôes funcionais entre esses elementos. Diversidade não é o número de coisas, mas o número de formas nas quais as coisas trabalham.

Apesar de a pesquisa científica ser fundamentada em ideias bem estruturadas, muitas vezes, está fora da realidade de quem a usa no cotidiano, já que dificilmente consideram fatores importantes como os valores culturais, educacionais, sociais, ambientais e/ ou econômicos, tornando-se necessária a construção do conhecimento de forma conjunta entre o saber local e o saber acadêmico, para a percepção da multidimensionalidade dos agroecossistemas familiares de base ecológica.

A partir do exposto, fica claro o desafio que se tem pela frente para construir um desenvolvimento mais próximo do sustentável, pois é necessário conhecer as inter-relaçôes e adicionar suas distintas dimensôes: sociais, econômicas, ecológicas, cultural, política e ética - não necessariamente nesta ordem - para se construir um "caminho do meio", norteado pela ética solidária, que permita alcançar uma nova racionalidade socioambiental (SACHS, 1993).

Desta forma, se faz necessária a construção de uma nova racionalidade dialética e desalienante, que amplie e complexifique nossa compreensão dos elementos que excedem a razão. Este é um movimento essencial para a realização de um desenvolvimento realmente sustentável (LAVORATTI, 2002). Para tanto, é necessário conhecer, respeitar e promover a cultura, a diversidade local, norteado pela ética social, abrindo espaço para esta nova racionalidade, bem como, para uma ética da outridade e para um diálogo de saberes. Um espaço onde o princípio da prevenção, diante da Sociedade de Risco não é apenas um critério marginal no processo de tomada de decisôes, mas sim o centro deste (LEFF, 2010).

No entanto, não se deve esquecer o alerta feito por Costabeber e Caporal (2003), para que antigos erros não sejam repetidos em nome da "sustentabilidade", pois muitas "práticas" ditas "ecológicas", como o caso da agricultura ecologizada, que não passa da incorporação de uma nova geração tecnológica e de insumos, para perpetuação de um modelo convencional de produção, e de desenvolvimento, frutos de uma tentativa de "dupla revoluçáo verde", que acaba por fomentar o limitado mercado do consumo verde.

\section{ALGUMAS CONCLUSÕES POSSÍVEIS}

1- As atividades realizadas pelos agricultores familiares na propriedade estudada indicam e caracterizam o sistema de produção como de base ecológica que apresentam os seguintes atributos: adaptabilidade, estabilidade, produtividade, resiliência, complexidade, equidade e autogestáo. Observase uma preocupaçáo na continuidade da busca da sustentabilidade deste agroecossistema, denotando-se uma referência com o social, com o ambiental, com o econômico, com o cultural, com o político e com o ético.

2- O trabalho realizado pelo casal é visualizado como uma ilha de especiarias num mar onde o oceano é algo tratado como homogêneo, onde estas especiarias estão relacionadas com a diversidade da produçáo e o homogêneo como a mesmice na produçáo convencional.

\section{REFERÊNCIAS}

ABRAMOVAY, R. Paradigmas do capitalismo agrário em questáo. 3.ed. São Paulo: Edusp, 2007. 296 p.

ALTIERI, M.A. Agroecologia: as bases científicas da agricultura alternativa. Rio de Janeiro: PTA/FASE, 1989.

ALTIERI, M.A. Agroecology: the scientific basis of alternative agriculture. Boulder: Westview Press, 1987.

BALSAN, R. Impactos decorrentes da modernização da agricultura brasileira. Campo- Território: revista de geografia agrária, Uberlândia, v.1, n.2, p.123-151, ago. 2006. Disponível em: <http://www.campoterritorio.ig.ufu.br/include/getdoc. php>. Acesso em: 28 mai. 2012. 
BERGAMASCO, S.M.P.P.; NORDER, L.A.C. O que são assentamentos rurais? São Paulo: Brasiliense, 1996.

BOURDIEU, P. Razóes práticas: sobre a teoria da ação. São Paulo: Papirus, 1996.

CAILLÉ, A. Nem holismo nem individualismo metodológicos: Marcel Mauss e o paradigma da dádiva. Revista Brasileira de Ciências Sociais, v.13, n.38, p.5-38, 1998.

CAPRA, F. A teia da vida. Ecologia Profunda - um novo paradigma / Das partes para o todo. São Paulo: Cultrix, 1996. 256p.

CAVALCANTE, P.A. Mudança e resistência: a experiência dos assentamentos rurais no município de Girau do Ponciano. Maceió, UFAL. 2007. Dissertação. (Mestrado em Sociologia) Programa de Pós-Graduação em Sociologia, Instituto de Ciências Sociais, Universidade Federal de Alagoas.

CHAMBERS, R.; PACEY, A.; THRUPP, L. A. Farmer first: farmer innovation and agricultural research. London, UK: Intermediate Technology Development Group, 1989. 219 p. COSTABEBER, J.A.; CAPORAL, F.R. Possibilidades e alternativas do desenvolvimento rural sustentável. In: VELA, H. (Org.). Agricultura familiar e desenvolvimento rural sustentável no Mercosul. Santa Maria: UFSM/Pallotti, 2003. p.157-194.

FLORES, M.X.; SILVA, J. Projeto EMBRAPA II: do projeto de pesquisa ao desenvolvimento socioeconômico no contexto do mercado. Brasília, DF: EMBRAPA-SEA, 1992. 55p. (EMBRAPA-SEA. Documentos, 8).

GORGEN, F.S.A.; STÉDILE, J.P. (Org.) Assentamentos: a resposta econômica da reforma agrária. Petrópolis: Vozes, 1991.

GRANOVETTER, M. Economic strength of weak ties. American Journal of Sociology, Chicago, v.78, n.6, p.13601380, May, 1973.

GUANZIROLI, C.E.; ROMEIRO, A.; BUAINAIN, A.M.; DI SABBATO, A.E.; BITTENCOURT, G. Agricultura familiar e reforma agrária no século XXI. Rio de Janeiro: Garamond, 2001. 288p.

GUANZIROLI, C.E.; FALCAO, A.P. Relação entre conflitos no campo e assentamentos rurais. Sociedade Brasileira de Economia, Administração e Sociologia Rural. In: CONGRESSO DA SOBER, 50., 2012, Vitória. Anais... Vitória, 22 a 25 de julho de 2012. (ISBN 978-85-98571-08-9).

GUZMAN CASADO, G.I.; GONZALEZ MOLINA, M.; SEVILLA GUZMAN, E. Bases teoricas de la agroecologia. In: GUZMAN CASADO, G.I.; GONZALEZ MOLINA, M.; SEVILLA GUZMAN, E. Introduccion a la agroecologia como desarrollo rural sostenible. Madrid: Mundi-Prensa, 2000.

HABERMEIER, K. Como fazer diagnóstico rápido e participativo da pequena produçáo rural. Recife: SACTES/ Centro Sabiá, 1995. 72p. (Série Metodologias Participativas).

IBGE (Instituto Brasileiro de Geografia e Estatística), 2006. Disponível em: <http://www.ibge.gov.br> Acesso em 28/09/2015. LEFF, E. Discursos sustentáveis. São Paulo: Cortez, 2010.

LOWE, P. et al. Networks in rural development: beyond exogenous and endogenous models. In: PLOEG, J.D.V.; DIJK, G.V. (Ed.). Beyond modernization: the impact of endogenous rural development. Assen: Van Gorcum, 1995, p.87-105.

MAUSS, M. Ensaio sobre a dádiva: forma e razão da troca nas sociedades arcaicas. In.__. Sociologia e Antropologia. São Paulo: Edusp, 1974, v.2, p.49-209.

MEDEIROS, L.S.; LEITE, S. Assentamentos rurais e mudanças locais: uma introdução ao debate. In: MEDEIROS, L. S.; LEITE,
S. (Orgs.). Assentamentos rurais mudança social e dinâmica regional. Rio de Janeiro: Mauad, 2004.

MOTA, D.M.; SCHMITZ, H.; FREITAS, M.N. Pesquisa em agricultura familiar: contribuição para o debate. Raízes, Campina Grande, v. 26, n. 1-2, p.128-139, 2007.

OLIVEIRA, A.U.; STEDILE, J.P. A natureza do agronegócio no Brasil. Fórum Nacional de Reforma Agrária: Cartilha da via campesina, maio de 2005.

PETERSEN, P.; ROMANO, J.D. Abordagens participativas para o desenvolvimento local. Rio de Janeiro: AS-PTA/ Actnoaid-Brasil. 1999. p.144.

PLOEG, J.D.V.D. Camponeses e impérios alimentares: lutas por autonomia e sustentabilidade na era da globalização. Porto Alegre: UFRGS, 2008.

POLANYI, K. A grande transformação: as origens da nossa época. 2.ed. Rio de Janeiro: Campus, 2000.

RADOMSKY, G.F.W. Reciprocidade, redes sociais e desenvolvimento rural. In: SCHNEIDER, S. (Org.). A diversidade da agricultura familiar. Porto Alegre: UFRGS, 2006. p.104-113.

RICHARDS, P. Indigenous agricultural revolution: ecology and food production in West Africa. Boulder: Westview Press, 1985.

RUAS, E.D. et al. Metodologia participativa de extensão rural para o desenvolvimento sustentável - MEXPAR. Belo Horizonte, março 2006. 134p.

SABOURIN, E. Dádiva e reciprocidade nas sociedades rurais contemporâneas. In: ENCONTRO NORTE E NORDESTE DE CIENCIAS SOCIAIS, 11., 2003, Aracajú. Anais... Aracajú: UFS, 2003, v.1, p.1-26.

SACHS, I. As cinco dimensões do ecodesenvolvimento. In: Estratégias de transiçáo para o século XXI: desenvolvimento e meio ambiente. São Paulo: Studio Nobel, 1993.

SACCO DOS ANJOS, F.; CALDAS, N.V. A horta agonizante: mercantilização da agricultura e transformaçôes nas práticas de autoconsumo entre famílias rurais do extremo sul gaúcho.

Pensamento Plural, v.5, p.151-169, 2009.

SCHMITZ, E. Abordagem sistêmica e a agricultura familiar. In: MOTA, D.M.; SCHMITZ, E.; VASCONCELOS, H.E.M. Sociedade brasileira de sistemas de produção. Aracajú: J. Andrade, 2005. 398p.

SCHMITZ, H.; MOTA, D.M.; SIMÓES, A. Métodos participativos e agricultura familiar: atualizando o debate. In: SEMANA DA CAPRINOCULTURA E OVINOCULTURA BRASILEIRAS, 4., 2004, Sobral. Anais... Sobral: Embrapa Caprinos, 2004. 26 p. [1 CD].

SCHNEIDER, S. (Org.). A diversidade da agricultura familiar. Porto Alegre: UFRGS, 2006.

SEVILHA-GUZMÁN, E.S. Agroecologia y desarrollo rural sustentable: una propuesta desde Latino América. In: ENCONTRO INTERNACIONAL SOBRE AGROECOLOGIA E DESENVOLVIMENTO RURAL SUSTENTÁVEL, julho de 2001, Anais... Botucatu: FCA/ UNESP, 2001.

SILVA, J.G. A modernizaçáo dolorosa: estrutura agrária, fronteira agrícola e trabalhadores rurais no Brasil. Rio de Janeiro: Zahar, 1982. $192 \mathrm{p}$.

SILVA, M.A.D. Assentamento e sustentabilidade. Sociedade e Cultura, Goiânia, v.4, n.1, jan./jul. 2001, p.85-103.

SILVESTRO, M.L. et al. Os impasses sociais da sucessáo hereditária na agricultura familiar. Florianópolis: Epagri. 
Brasília: Nead/Ministério do Desenvolvimento Agrário, 2001. TOLEDO, V.M.; CARARBIAS, J.; MAPES, C.; TOLEDO, C. Ecologia y autosuficiencia alimentaria. Mexico: SigloVeintiuno, 1985.

VERDEJO, M.E. Diagnóstico rural participativo: guia prático DRP. Brasília: MDA/Secretaria da Agricultura Familiar, 2006. $62 \mathrm{p}$.
WANDERLEY, M.N.B. Raízes do campesinato brasileiro. In: TEDESCO, J.C. Agricultura familiar: realidades e perspectivas. Passo Fundo: EDIUPF, 1999. (Capítulo 1) p.23-56.

WEID, J.M.V.D. Agroecologia: condição para a segurança alimentar. Agriculturas, v.1, n.0, setembro de 2004. 